Herz 2019 · 44:82

https://doi.org/10.1007/s00059-017-4658-y

Received: 21 October 2017

Accepted: 16 November 2017

Published online: 12 December 2017

(c) Springer Medizin Verlag GmbH, ein Teil von

Springer Nature 2017

CrossMark

F. M. Ucar

Department of Cardiology, Trakya UniversityHospital, Edirne, Turkey

\title{
Pacemaker follow-up after device replacement
}

To the Editor,

Curila et al. [1] reported that pacemaker reprogramming is rarely needed after device replacement. In their prospective study, they showed that outpatient visits after pacemaker replacement do not involve subsequent device reprogramming during follow-up. This suggests the potential benefit of remote follow-up for these patients.

The number of cardiac pacemaker implantations is increasing because of the aging population and the extended indications for device implantation [2]. In the United States alone, more than 100,000 pacemaker generator change procedures are performed annually [3]. Pacemaker technology has made great progress in recent years and pacemaker follow-up visits provide more information on heart rate histograms, heart rate variability, supraventricular or ventricular arrhythmia episodes, and patient activity etc. These data are very important for assessment of the patient's clinical status [4].

In this well-presented article, Curila and colleagues report that after device replacement, planned outpatient visits are not needed. Even if reprogramming is not performed, the data can be used for the patient's treatment and follow-up or for changing the device parameters. In light of this knowledge, it might be beneficial to follow up all patients with cardiac devices routinely.

\section{Corresponding address}

F. M. Ucar, MD

Department of Cardiology, Trakya

UniversityHospital

Edirne, Turkey

dr_fmucar@hotmail.com

Conflict of interest. F.M. Ucar declares that he has no competing interests.

\section{References}

1. Curila K, Smida J, Herman D, Osmancik $P$, Stros P, Zdarska J, Prochazkova R, Widimsky P (2017) Pacemaker reprogramming rarely needed after device replacement. Herz 27. https://doi.org/10. 1007/s00059-017-4627-5

2. Camm AJ, Nisam S (2010) European utilization of the implantable defibrillator: has 10 years changed the 'enigma'? Europace 12:1063-1069. https:// doi.org/10.1093/europace/euq282

3. Mond HG, Proclemer A (2011) The 11th world survey of cardiac pacing and implantable cardioverter-defibrillators: calendar year 2009 a World Society of Arrhythmia's project. Pacing Clin Electrophysiol 34:1013-1027

4. Uçar FM, Yilmaztepe MA, Taylan G, Aktoz M (2017) Non-sustained ventricular tachycardia episodes predict future hospitalization in ICD recipients with heart failure. Arq Bras Cardiol 2:0. https://doi.org/ 10.5935/abc.20170141 